\title{
TTR
}

Traduction, terminologie, re?daction

\section{Language and Culture in Translation: Competitors or Collaborators?}

\section{N. Komissarov}

Volume 4, numéro 1, 1st semester 1991

Languages and Cultures in Translation Theories

URI : https://id.erudit.org/iderudit/037080ar

DOI : https://doi.org/10.7202/037080ar

Aller au sommaire du numéro

Éditeur(s)

Association canadienne de traductologie

ISSN

0835-8443 (imprimé)

1708-2188 (numérique)

Découvrir la revue

Citer cet article

Komissarov, V. N. (1991). Language and Culture in Translation: Competitors or Collaborators? TTR, 4(1), 33-47. https://doi.org/10.7202/037080ar d'utilisation que vous pouvez consulter en ligne.

https://apropos.erudit.org/fr/usagers/politique-dutilisation/ 


\title{
Language and Culture in Translation: Competitors or Collaborators?
}

\author{
V.N. Komissarov
}

The title of this collection of papers sponsored by the International Federation of Translators outlines a direction of research which is of great theoretical and practical interest. Language and culture are obviously the two dominant factors which make translation an indispensable and most complicated kind of intellectual activity. Our world is a babel of languages and interlingual communication, that is communication between people speaking different languages, is impossible unless the linguistic barrier is overcome in some way. Thus language, or rather difference in languages, is the raison d'être of translation. We translate from one language into another to make interlingual communication possible. The idea of linguistic transfer is implicit in the very name of the phenomenon and a definition of the translating process usually makes some reference to language or languages.

The cultural factor in translation is also undeniable if not so obvious. No communication is possible unless the message transmitted through speech utterances (or texts) is well understood by the communicants. But this understanding can be achieved only if the information contained in language units is supplemented by background knowledge of facts referred to in the message. People belonging to the same linguistic community are members of a certain type of culture. They share many traditions, habits, ways of doing and saying things. They have much common knowledge about their country, its geography, history, climate, its political, economic, social and cultural institutions, accepted morals, taboos and many other things. All this information is the basis of the 
communicants presuppositions which enable them to produce and to understand messages in their linguistic form.

It is obvious that in interlingual communication involving members of two different cultures this common knowledge may be seriously limited which will be an obstacle to understanding. In other words, the translated message is transferred not only to another language but also to another culture. This fact cannot but influence the translating process. In addition to overcoming the linguistic barrier the translator has to surmount the cultural barrier, to make sure that the receptors of the target text are provided with the presuppositions required for their access to the message contents.

My apology for boring the reader with these well-known trivial facts is that their acceptance gives rise to a number of seminal theoretical problems which I propose to discuss in this paper.

Given the importance of the linguistic and cultural factors in translation, what are the relationships between them? Can a translation be made either on a linguistic basis or on a cultural one, or are they so interdependent that the one always implies the other? Can we speak about "linguistic" and "cultural" translations? Are we to choose between a linguistic theory or translation and a cultural (or ethnographic) one?

The answers to these questions involve the consideration of some broader theoretical issues. Do cultural differences really necessitate and justify substantial changes in the source text message to make it understandable to the target text receptors? How should the translator reconcile his loyalty to the source text and his concern about the target text receptors? In other words, what is the relative theoretical weight of translation equivalence and translation pragmatics? Obviously, some fundamental aspects of translation theory are involved here.

Let us begin with the first part of the title: "from language to language" and consider the role of languages and linguistic sciences in the theory and practice of translation. Much research has been done in the field of translation in the last few decades, which has resulted in the development of the linguistic theory of translation. 
The linguistic study of translation had to overcome many prejudices and doubts concerning the importance of the linguistic aspects of the translating process and the possibility of describing this process in linguistic terms. In 1956, E. Cary claimed that linguistics had nothing to do with translation which, in his opinion, was anything but a linguistic operation. E. Cary insisted that the role of language (or languages) in translation was negligible and could be compared with the role of notation in composition of music, that translation of a literary work was a literary process and that of a lyrical poem, a lyrical operation. ${ }^{1}$ E. Cary did not speak of technical translation but in the same line of argument one could claim that the translation of a paper on chemistry was a chemical process and the translation of a book on medicine is a medical operation.

Most of the doubts were related to the restricted concepts of language as the object of linguistic science. For some linguists the field of linguistic research should be limited to the so-called microlinguistics or internal linguistics in the Saussurian sense. Microlinguistics is concemed predominantly or even exclusively with language structure, viewing it as an immanent entity developing and functioning according to its own internal predispositions, apart from social, psychological or cognitive phenomena. Consequently, not only the study of specific ways language is used in speech communication, but also all attempts at analysing the meaning of language units must be considered non-linguistic. The main aim of microlinguistics is a formal description of the language system based on the interrelationships and interdependencies of its elements without any recourse to external factors. Such a description, it is presumed, would ensure the objectivity of analysis comparable to that of exact sciences.

Obviously, the translation situation which involves equivalent messages, that is speech units or texts, in two different languages is not part of the system of either of these languages and cannot be studied and described in terms of microlinguistics. On the strength of this reasoning the basic factors influencing the translating should be regarded as extralinguistic and a linguistic theory of translation is a misnomer and has no right to exist.

1. E. Cary. "Théories Soviétiques de la Traduction". Babel (vol. III, no. 4, 1957, p. 186). Cf. E. Cary, la Traduction dans le monde moderne (Genève, 1956). 
The restrictive concept of language and linguistics has been made obsolete by the development of linguistic sciences. The microlinguistic approach misses the language rationale which makes it the most important vehicle of civilization. It underestimates the main social function of language: to serve as a means of human communication and cognition. This function cannot be performed unless language is a system of meaningful units, an instrument to arrange information so as to make possible its exchange among communicants. No true insight into the nature of language is possible, therefore, without studying the ways different bits and elements of information are incorporated in various language units, without discovering how change of information is made through language units in actual speech under different circumstances. This focuses the linguist's attention upon the semantic aspect of language and various social, psychological, situational and other factors which influence the choice of a particular speech pattern.

It is in this direction that linguistics has been moving in the second half of the XXth century. Having made good progress in the study of linguistic form, it turned its attention to the semantic aspect of language, its semantic structure. Developing new concepts of semantic fields, sememic analysis and many others, it paved the way for a detailed description of the various strata of contents in speech utterances and integrated texts. New important branches of linguistics have emerged including sociolinguistics, psycholinguistics, contextual linguistics, text linguistics, pragmalinguistics, etc., which now ensure a more comprehensive, multidimensional approach to language, speech and verbal communication as a whole. Linguistics has become macrolinguistics in the broader sense of the term. Many phenomena that were considered extralinguistic even though they determined in some direct or indirect way the form and/or content of verbal utterances, have found their place within the new enlarged field of linguistic research.

These developments greatly enhanced the potential of linguistic research and made it possible for linguistics to meet the challenge of the translation explosion of the XXth century. More and more linguists began to turn their attention to the phenomenon of translation. There was a growing awareness that linguistics could no longer ignore this important type of language use, that, as 
M.A.K. Halliday put it, "the theory of translation is an important, if somewhat neglected aspect of general linguistics. ${ }^{\text {"2 }}$

Moreover, it became evident that the study of translation could be of great value to the further development of linguistics, as it could bring out certain features and possibilities in a language which could not be discovered in any other way. The linguists realized that translation is a sort of dynamic comparison of languages in action which gains a new insight into the way languages function in speech and reveals much of both their universal and specific features. The obvious conclusion was: "Any comparison of two languages implies an examination of their mutual translatability; widespread practice of interlingual communication, particularly translation activities must be kept under constant scrutiny by linguistic science. ${ }^{\prime 3}$

An additional impetus to the development of the linguistic theory of translation was given by the attempts to achieve automatic translation with the help of computers. After a promising start it was soon discovered that in order to teach the computer how to do this, we must first know a lot more about the linguistic mechanics of translation. This emphasized the need for an in-depth study of translation activities in general. Many linguists who were inspired by the prospects of automatic translation got interested in the problems of human translation and found it no less promising and absorbing field of research.

Much work has been done in universities and translators' training schools looking for a theoretical basis of their syllabuses and curricula. The results of linguistic research in translation were incorporated in theoretical and practical courses offered to future translators.

2. M.A. Halliday. "Linguistics and Machine Translation", in A. McIntosh and M.A. Halliday, Patterns of Language (London, 1966).

3. R. Jakobson. "On Linguistic Aspects of translation", in R.A. Brower ed. On Translation (New York, 1966, p. 234). 
At present the linguistic theory of translation is a body of theoretical thought embracing the most important aspects of interlingual communication. ${ }^{4}$

The core of the translation theory is the general theory of translation which is concerned with the fundamental aspects of translation inherent in the nature of interlingual communication and therefore common to all translation events, irrespective of what languages are involved or what kind of text and under what circumstances is translated. Basically, replacement of the source text by the target text of the same communicative value is possible because both texts are produced in human speech governed by the same rules and involving the same relationships between language, reality and the human mind. All languages are means of communication, each language is used to externalize and shape human thinking, all language units are meaningful entities related to nonlingualistic realities, all speech units convey information to the communicants. In each language communication is achieved through a complicated interpretation of the speech units by the communications, involving an assessment of the meaning of the language units against the background information derived from the contextual situation, general knowledge, previous experience, various associations and other factors. The general theory of translation deals, so to speak, with translation universals and is the basis for all other theoretical studies in this field, since it describes what translation is and what makes it possible.

An important part of the general theory of translation is the theory of equivalence aimed at studying semantic relationships between the source and the target text. There is a presumption of semantic identity between the translation and its source text. At the same time it is easily demonstrable that there is, in fact, no such identity, for even a cursory examination of any translation reveals inevitable losses, increments or changes of the information transmitted. Let us take an elementary case. Suppose we have an English sentence "The student is reading a book" and its Russian translation "Ступент читает книгу".

4. V. Komissarov. "Training Professional Translators: The Role of Translation Theory", Xth World Congress of FIT. Proceedings (Wien, 1985). 
This translation is a good equivalent of the English sentence but it is not identical in meaning. We can point out, for example, that the Russian sentence leaves out the meaning of the articles as well as the specific meaning of the Present Continuous Tense. In Russian we do not get the explicit information that it is some definite student but not any particular book, or that the reading is in progress at the moment of speech. On the other hand, the Russian sentence conveys some additional information which is absent from its English counterpart. We learn from it that the student in the case is a male, while in the source sentence it may just as well be a female. Then the translation implied that this student is college undergraduate, while in the English sentence he may be a high school student or even a scholar. To say nothing of the additional grammatical meaning conveyed by the grammatical aspect of "Читает" or by the gender of "Книга." Part of this information, lost or added in the translating process, may be irrelevant for communication, another part is supplemented or neutralized by the contextual situation. It is obvious, however, that translation equivalence does not imply an absolute semantic identity of the two texts. The theory of equivalence is concerned with factors which prevent such an identity, it strives to discover how close two texts in different languages can be and how close they are in each particular translation event.

The general theory of translation describes the basic principles which hold good for each and every translation event. In each particular case, however, the translating process is influenced both by the common basic factors and by a number of specific variables which stem from the actual conditions and modes of the translator's work: the type of the source text he has to cope with, the form in which the source text is presented to him and the form in which he is supposed to submit his translation, the specific requirements he may be called upon to meet in his work, etc.

Contemporary translation activities are characterized by a great variety of types, forms and levels of responsibility. The translator has to deal with the works of the great authors of the past and of the leading authors of today, with the intricacies of science fiction and the accepted stereotypes of detective stories. He must be able to cope with the elegancy of expression of the best masters of literary style and with the tricks and formalistic experiments of modern avant-gardistes. The translator has to preserve and fit into a different linguistic and social context a gamut of shades of meaning and stylistic nuances expressed in the source text by a 
great variety of language devices: neutral and emotional words, archaic words and new coinages, metaphors and similes, foreign borrowings, dialectal, jargon and slang expressions, stilted phrases and obscenities, proverbs and quotations, illiterate or inaccurate speech, and so on and so forth.

The source text may deal with any subject from general philosophical principles or postulates to minute technicalities in some obscure field of human endeavour. The translator has to tackle complicated specialized descriptions and reports on new discoveries in science or technology for which appropriate terms have not yet been invented. His duty is to translate diplomatic representations and policy statements, scientific dissertations and scathing satires, maintenance instructions and after-dinner speeches, etc.

Translating a play the translator must bear in mind the requirements of theatrical presentation, and dubbing a film he must see to it that his translation fits the movement of the speakers' lips.

He may be called upon to make his translation in the shortest possible time, at an official lunch or against the background noise of loud voices or rattling typewriters.

In conference interpretation the translator is expected to keep pace with the fastest speakers, to understand all kinds of foreign accents and defective pronunciation, to guess what the speaker meant to say but failed to express due to his inadequate proficiency in the language he is using.

In consecutive interpretation he is expected to listen to long speeches taking short notes, and then to produce his translation in a full or compressed form, giving all the details or only the main ideas.

In some cases his customers will be satisfied with a most general idea of the original message, in other cases the translator will be taken to task for the slightest omission or minor error.

Each type of translation has its own combination of factors influencing the translating process. The general theory of translation is supplemented, therefore, with a number of special translation theories identifying major types of translation work and describing the predominant features of each type. 
Another important branch of the theory of translation is concerned with the study of the source and target language units which can replace each other in the translating process. The creation of equivalent texts results in, and, in part, is dependent on, the equivalence of the correlated units in the two texts. In any two languages there are pairs of units which are of identical or similar communicative value and can replace each other in translation. The communicative value of a language element depends both on its own semantics and on the way it is used in speech. Therefore translation equivalence may be established between units occupying dissimilar places in the systems of respective languages. It follows that equivalent units cannot be identified before a certain amount of the target texts have been compared with their source texts.

It is obvious that a description of translation equivalents should be bilingual, that is, it should always relate to a definite pair of languages. Moreover, a bilingual theory of translation should describe two separate sets of equivalents, with either language considered, in turn, as the source language and the other as the target language. Nevertheless all bilingual theories of translation proceed from the same basic assumptions as to the classification of equivalents and their role in the translating process.

Of particular interest is that branch of the theory of translation which is concerned with the translating process itself, that is, with the operations required for passing over from the source text to the target text. It is a great challenge to the translation theory to discover how the translator does his work, what his mental processes are which ensure production in the target language of a text of identical communication value with the given source text. True, these processes are not directly observable but they can be studied, even though with a certain degree of approximation, in various indirect ways. This direction of the translation theory is of considerable practical value for it makes possible the description of particular methods of translation that can be used by the translator. The study of the translating process reveals both the translator's general strategy and specific techniques used to solve typical translation problems.

This outline of the main directions of linguistic research in the field of translations is, of necessity, sketchy and incomplete. It shows, however, that acceptance of translation as part of linguistic studies is warranted and productive. Translations are made from language to language, the translating process is a kind of language 
use in the specific conditions of interlingual communication and, like other language applications, it is within the scope of linguistics, that is to say, of macrolinguistics.

Now let us return to the other part of our theme: What does translation from culture to culture mean?

Numerous facts of the cultural differences between the two linguistic communities influencing the translating process are wellknown and they have been discussed in a great number of publications. As often as not, they are referred to as factors necessitating all kinds of pragmatic adaptation in translation.

The most common case of such adaptation is the necessity of providing additional information in the target text to compensate for the lack of some knowledge shared by the receptors of the source text. This case can be exemplified by the not infrequent practice of supplying proper and geographical names with the common names of the subjects they denote. Such names as Newsweek, Oregon, Columbia Pictures, Roy Rogers refer to well- known facts in American culture and do not need my explanation in the English original, but in the Russian translation they become Newsweek magazine, the state of Oregon, the Columbia Pictures film company and a Roy Rogers dinner or snack bar. Similarly, specific notions and phenomena unknown in the target language culture as "affirmative action", "money laundering", "dinner theater", or "date rape" will require additional information or explanation.

It has been pointed out that particular translation problems may arise in relation to various symbolic actions in the source language culture, which are absent in the target language culture or may have a different meaning there. For instance, whistling as a way to express admiration is not common in Russia and the Russian people do not make V-signs with their fingers.

Similar difficulties have to be overcome when translating various figurative and metaphorical expressions. The translator must make sure that the receptors of his translation will understand why one should not carry coals to Newcastle and that to lead a person by the nose means to subjugate him and not to deceive as implied by the identical expression in Russian. To ensure proper understanding the translator will provide additional information or use 
another Russian expression with a similar meaning or just explain the figurative meaning of the English idioms .

All this is part of the translator's main aim of bringing the original message over to the target language receptor. Understanding a message means interpreting it on the basis of the required background knowledge. If such knowledge is missing due to cultural differences, it should be supplied or compensated for. The translator renders into another language what the words in the original message mean in their culture. The cultural specifics influence the way the language units are used and understood. Culture finds its expression in the language and through the language. A linguistic theory of translation must incorporate the cultural aspect as well. Translation from language to language is ipso facto translation from culture to culture.

It follows from the above that an excessive emphasis on the cultural aspect of translation as opposed to its linguistic aspect is hardly warranted or productive. It can easily bring about some kind of ethnographic bias in translation theory like that which is so apparent in J. B. Casagrande's formula: "One does not translate LANGUAGES but CULTURES"6.

Even without a direct opposition to the linguistic theory of translation the ethnographic bias involves serious theoretical problems related to the nature of translation and its loyalty to the source text. This can be best exemplified by an analysis of the seminal contributions to the theory of translation made by $E$. Nida and his colleagues who are engaged in Bible translations. ${ }^{\text {? }}$

E. Nida is a prominent linguist and his approach to translation is largely language-oriented. At the same time many of his theoretical generalizations concerning the character and the aims of the translating process are not infrequently ethnographically biased.

5. V. Komissarov. "The Practical Value of Translation Theory". Babel (no. 4, 1985).

6. J.B. Casagrande. "The Ends of Translation." NAL (vol. XX, no. 4, 1954).

7. E. Nida. Toward a Science of Translating (Leiden, 1964). 
Of great theoretical interest is Nida's suggestion that translation theory should distinguish between two different types of translation equivalence: 1) "formal equivalence" when translation is fully oriented towards the source text trying to reproduce it in all possible detail, and 2) "dynamic equivalence" when translation is fully oriented towards its receptors in the target language trying to produce the desired communicative effect upon them. As the very opposition of the terms "formal" and "dynamic" implies, Nida's sympathies are wholly with the latter. It is presumed that the degree of "dynamic equivalence" should be evaluated not against the source text but against the receptors' reactions which are greatly dependent on their cultural background. E. Nida cites numerous examples illustrating that the cultural gap necessitates considerable changes in the message in the course of the translating process. He claims that the expression "as white as snow" has no meaning for the people living in a tropical country and should be replaced in translation with something they will understand, such as, for instance, "as white as the feather of an egret", that the Biblical "to greet one another with a holy kiss" may be misunderstood by the receptors for whom a kiss implies a totally different kind of relationship and should be replaced with something like "to give a hearty handshake all around", etc. Similar examples are given by his colleagues. In the Bible Jesus Christ says that he is "the bread of life", but since for some Mexican Indians "bread" is but so important as "tortillas", it is suggested that it is "tortillas" that should be used in translation. For the same reason "wolf" becomes "coyote", "fig tree" is translated as "apple-tree", and "half coconuts shells" are substituted for ordinary "cups".

Presumably all these examples are a true reflection of the Bible translators' practice aimed at bridging the gap between two different cultures. However, they can hardly be used as a basis for sweeping theoretical generalizations. We must first examine if this practice is sufficiently representative and, indeed, if it is just right. It can be argued that the Bible translations are an exceptional case both because of the kind of linguistic expression they have to deal with, and the specific aims pursued by the translators. The language of the Bible is often figurative, sometimes obscure or mystical. The Bible story is deeply rooted in the culture of a people who lived

8. J. Beekman. "Lexical Equivalence Involving Consideration of Form and Function", in Notes on Translation with Drills (Santa Ana, Calif., 1965). 
thousands of years ago, the cultural gap is obviously great and the translator is naturally much concerned with it.

The present-day translators of the Bible do their work with a very specific aim. They are missionaries rather than just translators: they want their translation to influence the receptors, to make them accept the translation as a sacred book, and to convert them or to strengthen their faith. The translator does his best to remove the cultural differences which may in any way alienate the receptors, hinder their understanding of the Bible's message, or prevent them from accepting the Book as their own.

What is still more important is that the Bible translators of today offer their translations to a very specific type of receptors: members of small ethnic communities in Africa or South America who are more or less isolated from world culture. The translators seem to believe that their receptors are more culture-bound and less open to different cultures than more advanced societies are. Obviously they do not think much of their receptors' ability to learn and to understand new things and ideas. Otherwise they would not think them unable to imagine that other people may value bread more than tortillas. (Or even if they do, the phrase "I am the bread of life" will not impress them as the translator wants them to be impressed).

Admitting the importance of the specific goal pursued by the Bible translators, one may ask whether the right way to achieve it is to replace the artefacts of one culture with those of the other one. S. Bassnett-McGuire dismissed the whole concept of Nida's dynamic equivalence by claiming that "to give one another a hearty handshake all around" is just a bad translation of "greeting with a holy kiss"9. Undoubtedly, E. Nida's ideas deserve a more detailed analysis, but the cultural adaptation advised by him does create a number of problems. The dynamic equivalence concept results in the receptors getting a false impression that the source language culture does not much differ from their own. The procedure does not bridge the cultural gap but rather pretends that it never existed. The receptors get access to a different story set in a familiar environment. The history of literature in many countries shows examples of such cultural adaptation when the original story is

9. S. Bassnett-McGuire, Translation Studies, Ch. 1. (Methuen, London and New York, 1980). 
transplanted to another soil (suffice it to recall West Side Story and its Shakespearean prototype), but to call them translations means stretching the meaning of the term too much.

Translation is an important vehicle for intercultural contacts. Translating from culture to culture means, first and foremost, to bring to the receptors new facts and ideas inherent in the source language culture, to broaden their cultural horizons, to make them aware that other people may have different customs, symbols and beliefs, that other cultures should be known and respected. This cultural and educational role of translation cannot be too much emphasized.

The ability of the receptors to understand and overcome cultural differences in receiving the source text message should not be underestimated. Even within one and the same culture there are numerous subcultures and subdivisions and people are used to other people talking, acting and believing differently from themselves. A Russian reader can readily accept the fact that a Bulgarian shakes his head in assent, that in Britain they drive on the left side of the road, or that in India the cow is a sacred animal. Reading in Shakespeare's sonnet: "Shall I compare thee to a summer's day" the native of a tropical land where summer is not a pleasant season, can still understand that the poet meant the comparison to be complimentary and that obviously in his culture summer is viewed differently. I would even suggest that the expression "as white as snow" can be well understood by a person who has never seen a snowdrift: he will guess that it is something extremely white.

If necessary, it can always be explained to him what it is, or shown in a picture. The problem may seem more complicated if the target language has no specific word for "white" but in this case the translator would have to cope with the familiar task of translating an equivalent-lacking word.

The translator has to do not with the cultural facts per se but with their names and verbal descriptions in the source text. In many instances a cultural problem in translation can be reformulated as a language problem and handled as similar language problems of noncultural origin. For example, the English idiom "to get up on the wrong side of the bed" could not have been coined in the Russian culture where beds were not usually put in the middle of the room but pushed against the wall or the stove. Contrariwise, the phrase "to wash dirty linen in public" though also 
an English idiom, refers to a procedure possible both in the English and Russian cultures. At the same time both idioms belong to the same type of translation problems: neither has any identical equivalent in Russian but can be easily translated with Russian idioms based on different figures of speech $^{10}$.

To sum up:

1. The linguistic and cultural aspects of translation need not be opposed for they are complementary. Cultural (ethnographic) translation problems can usually be reformulated as language problems and incorporated in the linguistic theory of translation.

2. The differences in the source language and target language cultures may necessitate additional information in the target text explaining unfamiliar facts and ideas to the receptors. In other cases they may result in omission of irrelevant details. Both addenda and omissions are typical translation procedures, not necessarily caused by cultural differences.

3. Orientation towards the target text receptors means concern for their adequate understanding of this source text message. Any type of equivalence implies a loyalty to the source text which is the hallmark of true translation.

4. It is expedient to draw a line of demarcation, both in theory and practice, between translation and various types of pragmatic adaptations, which may more or less depart from the original message to achieve some specific pragmatic goal.

10. V. Komissarov. "The Practical Value of Translation Theory", Loc. cit. 